\title{
Day vs. night non-invasive respiratory intervention during post-acute care hospitalization
}

\author{
Jane O’Brien ${ }^{1}$, Helene Dumas ${ }^{1}$, M. Laurette Hughes ${ }^{1}$, Brittany Ryan ${ }^{1}$, and Virginia \\ Kharasch $^{1}$ \\ ${ }^{1}$ Franciscan Children's Hospital
}

February 10, 2022

\begin{abstract}
Objective To compare daytime and nighttime use and outcome for non-invasive respiratory intervention (NIRI) during initial admission to a pediatric post-acute care hospital (PACH). Method Retrospective examination of initial PACH admissions (October 2018 through September 2020) for infants and children requiring NIRI during the day and night. Measures included: 1) Demographics (e.g. age, diagnostic group); 2) Daytime and nighttime NIRI type (supplemental oxygen therapy via low flow nasal cannula or positive airway pressure (PAP) via high-flow nasal cannula, continuous positive airway pressure (CPAP), or biphasic positive airway pressure (BiPAP) at admission and discharge; and 3) Outcome (reduction, increase, or no change) in NIRI support for daytime and nighttime from admission to discharge. Results Thirty-eight infants and children (mean age $=3.64$ years; premature infants, $\mathrm{n}=20$, other diagnoses, $\mathrm{n}=18)$ were included. For the total sample $(\mathrm{n}=38)$, daytime vs. nighttime NIRI type was significantly different $(\mathrm{p}<.001)$. At both admission and discharge, supplemental oxygen was the most common NIRI during the day, while PAP was most common at night. From admission to discharge, 7 (18\%) children had a positive change (reduced NIRI) during the day, while 9 (24\%) had a positive change at night. At discharge, 11/38 (29\%) children required no daytime NIRI, while 4/38 (11\%) required no day or night NIRI. Conclusion NIRI type differs between day and night at PACH admission and discharge. Reductions in NIRI were achieved during the day and at night from PACH admission to discharge for premature infants and for children with congenital or neurological diagnoses.
\end{abstract}

\section{Hosted file}

ManuscriptSubmissionCopy.docx available at https://authorea.com/users/459762/articles/ 555912-day-vs-night-non-invasive-respiratory-intervention-during-post-acute-carehospitalization

\section{Hosted file}

Table 1.docx available at https://authorea.com/users/459762/articles/555912-day-vs-nightnon-invasive-respiratory-intervention-during-post-acute-care-hospitalization

\section{Hosted file}

Table 2.docx available at https://authorea.com/users/459762/articles/555912-day-vs-nightnon-invasive-respiratory-intervention-during-post-acute-care-hospitalization 